\title{
Synthesis of zeolite P from sewage sludge ash
}

\author{
Jolanta Latosińska ${ }^{1, *}$ \\ ${ }^{1}$ Kielce University of Technology, Faculty of Environmental, Geomatic and Energy Engineering, Al. \\ Tysiąclecia Państwa Polskiego 7, 25-324 Kielce, Poland
}

\begin{abstract}
Sewage sludge is an example of waste considered as biomass. The utilization of sewage sludge is more often realized through combustion, which simultaneously constitutes the recovery of energy from a renewable source. However, the obtained ash requires neutralization. An alternative method for landfilling of sewage sludge ash is its conversion into synthetic zeolites. One of them is Zeolite P. The study shows the results of the synthesis of zeolite $\mathrm{P}$ from sewage sludge ash by chemical conversion. The conversion of sewage sludge ash was conducted at the activation temperatures of $60^{\circ} \mathrm{C}$ and $90^{\circ} \mathrm{C}$, crystallization temperatures of $60^{\circ} \mathrm{C}$ and $90^{\circ} \mathrm{C}$, crystallization time of 72 hours and the SSA:NaOH ratio of 1:1.4. The research of sewage sludge ashes after zeolitization included the observation of changes of ash particles surface, the identification of crystalized phases, cation exchange capacity (CEC) and specific surface area. The optimal synthesis conditions for zeolite $\mathrm{P}$ are the activation and crystallization temperatures of $90^{\circ} \mathrm{C}$. CEC of modified sewage sludge ashes is greater than CEC of sewage sludge ash. The presented method of sewage sludge ash conversion allows to obtain a usable material.
\end{abstract}

\section{Introduction}

Municipal sewage sludge is considered to be a renewable source of energy [1]. Its combustion causes the formation of sewage sludge ash. Sewage sludge ashes contain mainly $\mathrm{SiO}_{2}, \mathrm{Al}_{2} \mathrm{O}_{3}$, respectively 39.0-50.6 wt \%, 12.8-19.1 wt \% [2-6]. The composition of sewage sludge ashes is similar to the composition of coal fly ashes, because coal fly ashes mainly contain $32.2-$ $53.3 \mathrm{wt} \%$ of $\mathrm{SiO}_{2}$ and 4.0-32.2 wt $\%$ of $\mathrm{Al}_{2} \mathrm{O}_{3}$ [7-8]. The coal fly ashes are one of the raw materials used to synthesize zeolites [9-16]. It predisposes the use of sewage sludge ash for the synthesis of zeolites [17].

Zeolites are categorized into natural and synthetic groups [18-19]. Zeolites are hydrated crystalline aluminosilicates composed of tetrahedral $\mathrm{TO}_{4}$ units $(\mathrm{T}=\mathrm{Si}$ or $\mathrm{Al})$, which are linked together by oxygen atoms to form regular intercrystalline cavities and channels of atomic dimensions [20]. Due to significant adsorption and cation exchange capacity, large specific surface area, rich micropore, high thermal, mechanical and chemical stability, zeolites are commonly used as adsorbents, catalysts, ion exchangers, liquid and gas separation and membranes [20-21].

\footnotetext{
* Corresponding author: jlatosin@tu.kielce.pl
} 
One of the most interesting zeolites among different types of synthetic zeolites is zeolite P. It is characterized by two sets of channels: $0.31 \mathrm{~nm} \times 0.44 \mathrm{~nm}$ and $0.26 \mathrm{~nm} \times 0.49 \mathrm{~nm}$ [22]. Zeolite $\mathrm{P}$ is useful for gas separation, removal of toxic and radioactive waste, heavy metals and ammonium from wastewater and the formation of environmental friendly detergents [2324]. According to International Zeolite Association, the structure of zeolite $P$ has the same framework topology as gismondine [25-26].

Different methods of the synthesis of zeolites from ashes are known, i.e. a direct hydrothermal method [11-13; 27], an indirect fusion followed by a hydrothermal method [14,28-29], a two-step hydrothermal method [16] and a molten salt liquid free method [30$31]$.

The process of fly ash zeolitization is generally based on three stages: (i) dissolution of $\mathrm{Si}^{4+}$ and $\mathrm{Al}^{3+}$ ions from the initial aluminosilicates in alkaline solution; (ii) condensation of aluminosilicates hydrogel on undissolved particles of ash and (iii) the crystallization of zeolite and its growth [32].

Based on the literature study, only few examples of zeolitization of sewage sludge ash are known. Lee et al. [33] synthesized zeolites from sewage sludge fly ash by the hydrothermal method. The small quantity of zeolite $\mathrm{P}$ was synthesized in $1 \mathrm{~N}$ of $\mathrm{NaOH}$ solution. While a relatively large amount of hydroxy sodalite was synthesized in $3 \mathrm{~N}$ and 5 $\mathrm{N}$ of $\mathrm{NaOH}$ solution with a similar peak intensity.

According to Molina and Pole [9] indirect fusion method gives better results of zeolitization of coal fly ash compared to the direct hydrothermal method. Fusion step may transform the crystalline structure into noncrystalline form that is readily soluble in water, and thereby increase the zeolite formation during hydrothermal stage [34].

The aim of this research was the investigation of the possibility to synthesize zeolite $\mathrm{P}$ from sewage sludge ash. Indirect fusion treatment was used as the method of the synthesis. The study covered the tests on the influence of the activation temperature and the crystallization temperature on the conversion of sewage sludge ash.

\section{Materials and methods}

\subsection{Materials}

Sewage sludge ash used for the conversion was obtained as a result of sewage sludge incineration in a laboratory Naberthem furnace. The sample of sewage sludge was delivered from a municipal wastewater treatment plant in Sitkówka-Nowiny near Kielce. The wastewater treatment plant receives sewage from Kielce agglomeration, located in the central part of Poland.

Sewage sludge was dried in a laboratory drier at $105^{\circ} \mathrm{C}$ within 24 hours. Then, it was crushed in a mortar grinder to a fraction $<125 \mu \mathrm{m}$. Sewage sludge was incinerated at the temperature of $600^{\circ} \mathrm{C}$ within 11 minutes. After the combustion, the sample remained in the furnace until it cooled down to the temperature of $20^{\circ} \mathrm{C}$.

\subsection{Methods of zeolite synthesis}

The following conditions of the synthesis by indirect fusion method were applied: $10 \mathrm{~g}$ of sewage sludge ash was mixed and ground with $14 \mathrm{~g}$ of $\mathrm{NaOH}$ to obtain a homogeneous mixture. The mixture was heated in a laboratory furnace at the temperature of $550^{\circ} \mathrm{C}$ for 1 hour in air atmosphere. The sintered mixture was ground and mixed with distilled water (the applied concentration $3 \mathrm{~N} \mathrm{NaOH}$ ), followed by an aging process with an agitation in a shaking water bath at a given temperature within 12 hours. Then the mixture was crystallized 
under static conditions at the given temperature within 72 hours (tab.1). After the crystallization, the sample was washed with distilled water until the $\mathrm{pH}$ of solution reached 10.0 , then dried at $105^{\circ} \mathrm{C}$ for 10 hours.

Table 1. Temperatures of synthesis by indirect fusion method.

\begin{tabular}{|c|c|c|}
\hline Sample & Activation temperature, $^{\circ} \mathbf{C}$ & Crystallization temperature, ${ }^{\circ} \mathbf{C}$ \\
\hline S1 & 60 & 60 \\
\hline S2 & 60 & 90 \\
\hline S3 & 90 & 60 \\
\hline S4 & 90 & 90 \\
\hline
\end{tabular}

\subsection{Characterization methods}

The chemical compositions of sewage sludge and sewage sludge ash were determined by using the X-ray fluorescence spectroscopy. Phase analysis of sewage sludge ash and sewage sludge ash after the zeolitization was performed with the X-ray diffraction (XRD) using diffractometer. The identification of phases was performed by the comparison of the recorded diffractograms and the benchmarks found in a base ICDD PDF-2 and PDF-4+ 2014.

The morphological forms and the chemical composition of the main mineral components of samples in the micro area were determined using the scanning electron microscopy (SEM). The equipment used was a QUANTA FEG 250 scanning electron microscopy, which was equipped with a chemical composition analysis system based on the energy dispersion scattering (EDS).

The cation exchange capacity (CEC) was determined with the use of ammonium acetate. $\mathrm{CEC}$ is a measurement of the number of cations in the channels by unit weight that may be replaced by other ions in solutions. The exchangeable cations of samples were replaced by $\mathrm{NH}_{4}{ }^{+}$using $1 \mathrm{M}$ ammonium acetate [35]. The concentration of ammonium ions in solutions was determined with the use of ion chromatography.

Specific density was measured with the use of a helium pycnometer Micromeritics. Specific surface area (SBET) was determined on the basis of Braunauer-Emmett-Teller's multilayer adsorption theory (BET) at $\mathrm{p} / \mathrm{p}_{\mathrm{o}}$ between 0.05 and $0.25(\mathrm{p}-$ absolute pressure measured precisely at the moment when adsorption balance is reached, $\mathrm{p}_{\mathrm{o}}$ - nitrogen vapor pressure at the current atmospheric pressure at the time of measurement). Adsorbate used is nitrogen at $-195.50^{\circ} \mathrm{C}$. Diameters of pores Dp were calculated according to the equation $4 \cdot \mathrm{Vp} / \mathrm{SBET}$.

\section{Results and discussion}

The chemical compositions of sewage sludge used was shown in [36]. The main components of sewage sludge ash are $\mathrm{SiO}_{2}$ (20.8\% mas.), $\mathrm{Al}_{2} \mathrm{O}_{3}\left(5.28 \%\right.$ mas.), $\mathrm{P}_{2} \mathrm{O}_{6}(19.4 \%$ mas.), $\mathrm{Fe}_{2} \mathrm{O}_{3}\left(9.45 \%\right.$ mas.), $\mathrm{CaO}$ (14.3\% mas.). The ratio of $\mathrm{SiO}_{2}$ to $\mathrm{Al}_{2} \mathrm{O}_{3}$ of sewage sludge ash equals 3.94. Sewage sludge ash consists of: amorphous substance - 76.71\% mas., quartz - $9.12 \%$ mas., calcite $4.06 \%$ mas., dolomite - $3.28 \%$ mas., muscovite - $4.42 \%$ mas., potassium feldspar $-1.72 \%$ mas., plagioclase $-0.47 \%$ mas. and other $-0.22 \%$ mas.

The XRD diffractograms are presented in figure 1. Diffractograms of samples S1 and S3 indicate that zeolites are not formed while obtained phases are apatite, quartz and magnetite. 
Diffractograms of samples S2 and S4 show that except for apatite, quartz and magnetite, zeolite $\mathrm{P}$ is also formed.

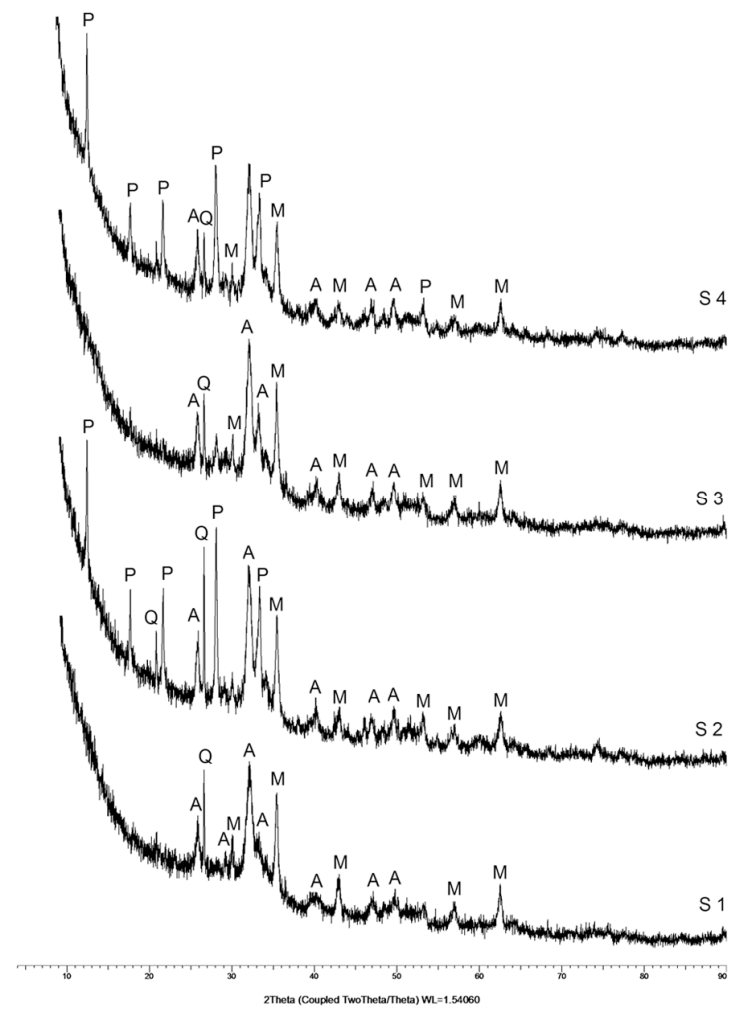

Fig. 1. XRD of samples S1-S4; A- apatite, M-magnetite, Q - quartz, P - zeolite P

Figure 2 shows the SEM micrograph of the original sewage sludge ash. Sewage sludge ash occurs as no porous and rough structure. The SEM images of the samples S1-S4 are presented in figure 3-6. The SEM results clearly show that the morphology of samples strongly depends on the crystallization temperature. In the case of samples S1 and S3, which are obtained in low crystallization temperature, the structures occur without crystalline forms. Whereas, samples S2 and S4 obtained as a result of the crystallization at the temperature of $90^{\circ} \mathrm{C}$ are characterized by a clear crystalline structure typical for zeolite P. Zeolite P occurs above $5 \mu \mathrm{m}$ aggregates with a lamellar and acicular form ( fig.6).
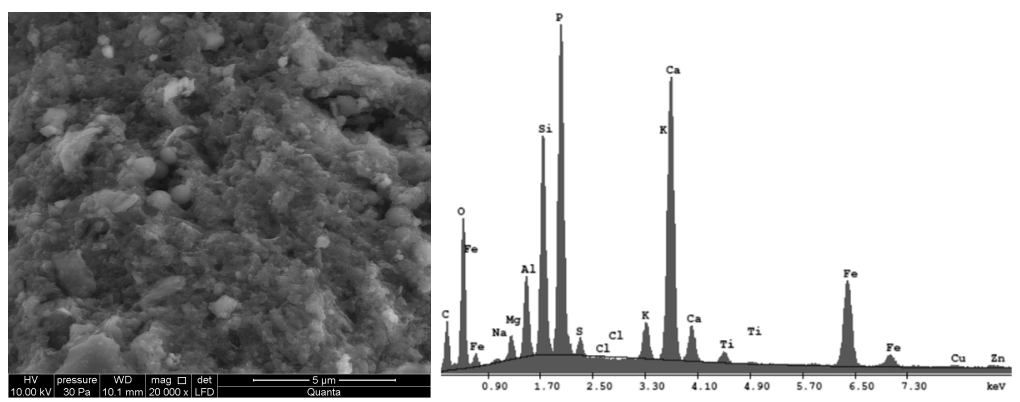

Fig.2. Scanning electron microscopy image (SEM) of SSA with chemical analysis (EDS) 

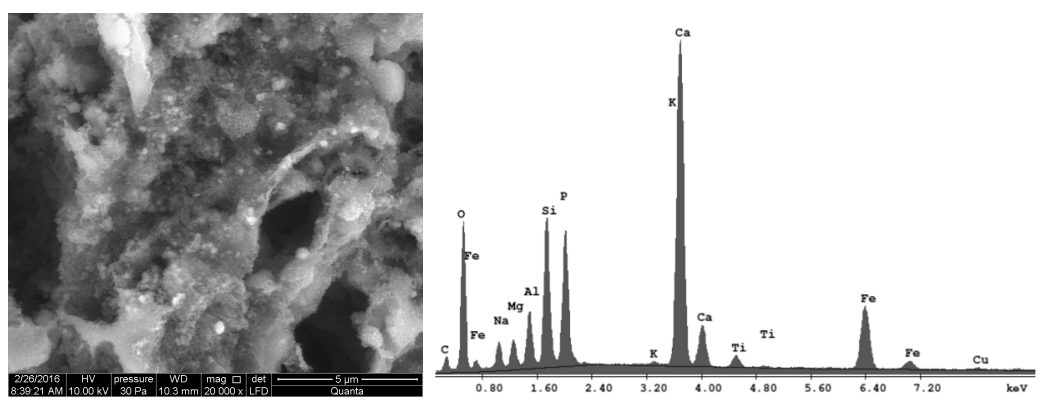

Fig. 3. Scanning electron microscopy image (SEM) of S1 with chemical analysis (EDS)
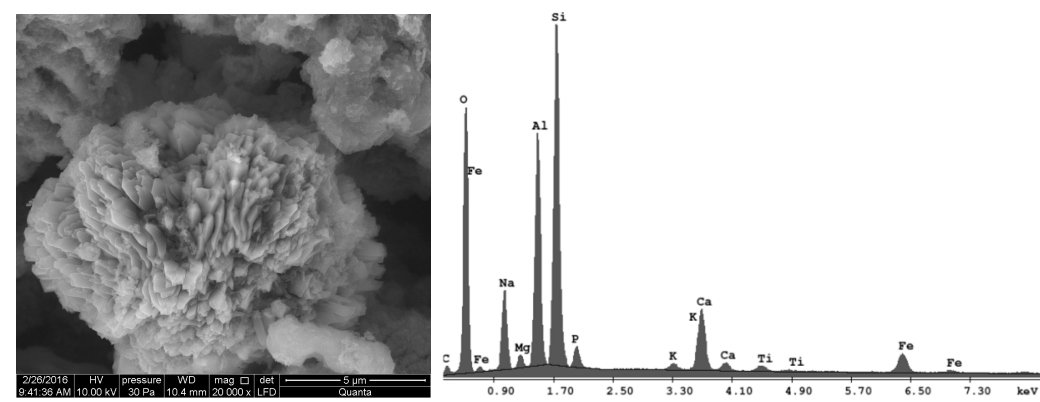

Fig.4. Scanning electron microscopy image (SEM) of S2 with chemical analysis (EDS).
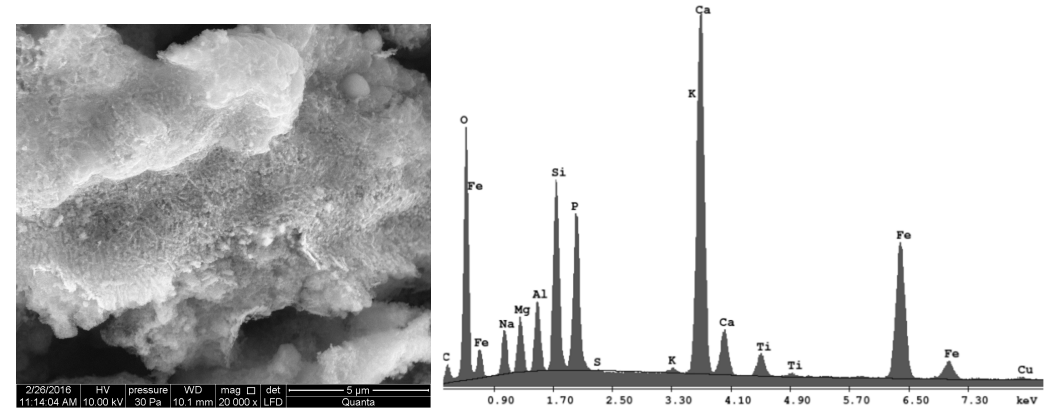

Fig. 5. Scanning electron microscopy image (SEM) of S3 with chemical analysis (EDS)
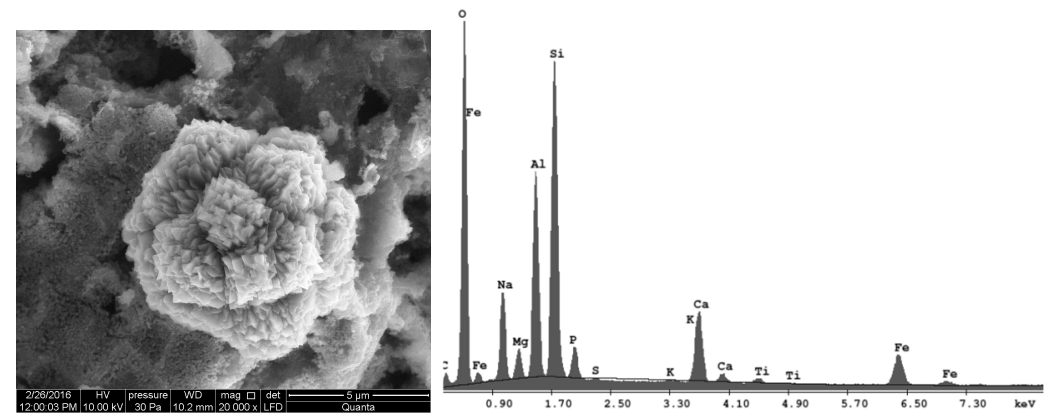

Fig. 6. Scanning electron microscopy image (SEM) of S4 with chemical analysis (EDS)

The analysis of the chemical composition of sewage sludge ash (fig.2) proves that one of the main elements except for $\mathrm{Ca}$ and $\mathrm{Si}$ is $\mathrm{P}$. Samples $\mathrm{S} 1$ and $\mathrm{S} 3$ crystallized at the 
temperature of $60^{\circ} \mathrm{C}$ were characterized by the greatest contribution of $\mathrm{Ca}$ (fig.3, fig.5). Whereas, due to the crystallization at the temperature of $90^{\circ} \mathrm{C}$ samples S2 and S4 had the greatest contribution of Si (fig.4, fig.6).

Table 2. Properties of sewage sludge ash and samples S1-S4.

\begin{tabular}{|c|c|c|c|c|}
\hline Sample & $\mathbf{C E C}, \mathbf{m e q} \cdot \mathbf{1 0 0 g}^{-1}$ & $\begin{array}{c}\text { Specific density, } \\
\mathbf{g}^{\mathbf{c}} \mathbf{m}^{-3}\end{array}$ & $\mathbf{B E T}, \mathbf{~ m}^{\mathbf{2}} \cdot \mathbf{g}^{-\mathbf{1}}$ & $\mathbf{D}_{\mathbf{p}}, \mathbf{n m}$ \\
\hline SSA & 49.668 & 2.51 & 63.3510 & 5.56481 \\
\hline S1 & 189.562 & 2.64 & 171.5127 & 1.25154 \\
\hline S2 & 264.884 & 2.14 & 107.3380 & 1.21818 \\
\hline S3 & 209.720 & 2.97 & 154.5762 & 1.25732 \\
\hline S4 & 268.282 & 3.30 & 97.4626 & 1.22326 \\
\hline
\end{tabular}

Specific density of sewage sludge ash equals $2.51 \mathrm{~g} \cdot \mathrm{cm}^{-3}$ and is comparable to specific density of sewage sludge ash after conversion. Sample S2 has the smallest specific density $2.14 \mathrm{~g} \cdot \mathrm{cm}^{-3}$, while sample S4 has the greatest specific density $-3.3 \mathrm{~g} \cdot \mathrm{cm}^{-3}$.

The possibility of practical use of zeolitic materials depends mainly on the cation exchange capacity and specific surface area. The cation exchange capacities of sewage sludge ash and samples S1-S4 are shown in table 2. The conversion of sewage sludge ash resulted in the increase of CEC in comparison to CEC of sewage sludge ash from 3.8 to 5.5 times respectively. The samples after crystallization at a higher temperature have CEC from 264.884 to $268.282 \mathrm{meq} \cdot 100 \mathrm{~g}^{-1}$. Whereas, the samples after crystallization at the temperature of $60^{\circ} \mathrm{C}$ have CEC 189.562 and $209.72 \mathrm{meq} \cdot 100 \mathrm{~g}^{-1}$ respectively. CEC of samples S1-S4 is higher than CEC of sludge from the drinking water plant after the conversion with the fusion method [37].

Calculated by the BET method, specific surface area increases after the conversion because of the texture of pores of samples structure. Specific surface area of samples after crystallization at the temperature of $60^{\circ} \mathrm{C}$ is a little higher than of samples after crystallization at the temperature of $90^{\circ} \mathrm{C}$ (tab.2.). Sample $\mathrm{S} 1$ has the greatest value of specific surface area, and samples $\mathrm{S} 4$ the smallest, 171.51 and $97.46 \mathrm{~m}^{2} \mathrm{~g}^{-1}$ respectively.

The specific surface area of samples S1-S4 is higher than in the literature data. Yang et. al. proved that fly ash from combustion of municipal sewage sludge after the conversion with the hydrothermal method had the specific surface area at the level of $24-52 \mathrm{~m}^{2} \mathrm{~g}^{-1}$ [38].

The diameter of pores for sewage sludge ash equals $5.564 \mathrm{~nm}$ and is greater than the diameter of pores of sewage sludge ash after zeolitization. The conditions of conversion do not have an important impact on the diameter of pores. Samples S1-S4 have the diameters of pores from 1.218 to $1.251 \mathrm{~nm}$. The pores of samples S1-S4 are smaller than the ones of fly ash after the combustion of municipal wastes after the conversion with the fusion method, 4.0-7.8nm [3].

\section{Conclusions}

In this study, the synthesis of zeolite P from sewage sludge ash was investigated by the use of an indirect fusion method. The synthesis of zeolite $\mathrm{P}$ was dependent on the activation temperature and the crystallization temperature. The optimal synthesis conditions for zeolite $\mathrm{P}$ on the basis of diffractograms were the activation and crystallization temperatures of $90^{\circ} \mathrm{C}$. 
The conducted research proved that sewage sludge ash after zeolitization is characterized by better ion-exchange properties and specific surface area than sewage sludge ash. The above-mentioned facts allow for the use of the obtained materials as sorbents for sewage contaminants, particularly heavy metals.

The project was funded by the National Science Centre allocated on the basis of the decision DEC2011/03/D/ST8/04984, in Poland

\section{References}

1. Directive 2012/27/EU of the European Parliament and of the Council of 25 October (2012)

2. C.M.A. Fontes, M.C. Barbosa, R.D. Toledo Filho, J.P. Goncalves, Potentiality of sewage sludge ash as mineral additive in cement mortar and high performance concrete. Use of Recycled Materials in Building and Structure (2004)

3. K.S. Wang, I.J. Chiou, Ch.H. Chen, D. Wang, Constr Build Mater. 19, 627-633 (2005)

4. C.H. Chen, I.J. Chiou, K.S. Wang, Cement Concrete Comp. 28, 26-32 (2006)

5. S.C. Pan, C.C. Lin, D.H. Tseng, Conservation and Recycling 39, 79-90 (2003)

6. J. Latosińska, EPE Journal 44, 105-122 (2017)

7. W. Franus, M.M. Wiatros-Motyka, M. Wdowin, Environ. Sci. Pollut. Res. 22, 9464 (2015)

8. M. Żygadło, A. Seweryn, M. Woźniak, J. Latosińska, Probl. Sustainable Development 6, 207 (2011)

9. A. Molina, C. Poole, Mineral Engineering. 17, 167 (2004)

10. M-G. Lee, G. Yi, B. Ahn, F. Roddick, Korean J Chem Eng 17, 325 (2000)

11. W. Franus, Pol J Environ Stud 21, 337 (2012)

12. N. Murayama, H. Yamamoto, J. Shibata, Int J Miner Process, 64, 1 (2002)

13. R. Moriyama, S. Takeda, M. Onozaki, Y. Katayama, K. Shiota, T. Fukuda, Y. Tani, Fuel. 84, 1455 (2005)

14. N. Shigemoto, H. Hayashi, K. Miyaura, J Mat Sci 28, 4781 (1993)

15. D. Wu, Y. Sui, S. He, X. Wang, C. Li, H. Kong, J Hazard Mater 155, 415 (2008)

16. H. Tanaka, S. Furusawa, R. Hino, J Mater Synthetic Processing 10, 143 (2002)

17. J. Latosińska, JEE 17, 138-146 (2016)

18. D. Paliulis, Pol J Environ Stud 25, 251 (2016)

19. Vk. Jha, M. Nagae, M. Matsuda, J Environ Manage 90, 2507 (2009)

20. S. Bohra, D. Kundu, M.K. Naskar, Ceram Int 40, 1229 (2014)

21. L. Deng, Q. Xu, H. Wu, Procedia Environ Science 31, 662 (2016)

22. I. O. Ali, S. M. El-Sheikh, T. M. Salama, M. F. Bark, M. H. Fodial, Sci China Mater $\mathbf{5 8 ,} 621(2015)$

23. M. Atkins, FP. Glasser, J.J. Jack, Waste Manage. 15, 127 (1995)

24. JG. Nery, YP. Mascarenhas, AK. Cheetham, Microporous and Mesoporous Mater. 57, 229 (2003)

25. J.H. Dong, Ys. Lin, Ind Eng Chem Res 37, 2404 (1998)

26. D. Berck, Zeolite Molecular Sives. (John Wiley \& Sons. New York. USA 1974)

27. C.S. Cundy, P.A. Cox, Microporous and Mesoporous Mater. 82, 1 (2005)

28. K. Ojha, N.C. Pradhan, A.N. Samanta, B Mater Sci 27, 555 (2004)

29. H. Kazemian, Z. Naghdali, T.G. Kashani, F. Farhadi, Adv Powder Technol 21, 279 (2010)

30. M. Park, C.L. Choi, W.T. Lim, M.C. Kim, J. Choi, N.H. Heo, Microporous and Mesoporous Mater. 37, 81 (2000)

31. B. Prasad, Water Air Soil Poll 218, 667 (2011) 
32. X. Querol, N. Moreno, J. C. Umana, A. Alastuey, E. Harnandez, A. Lopez-Soler, Int J Coal Geol 50, 413 (2002)

33. M-G. Lee, G. Yi, B. Ahn, F. Roddick, Korean J Chem Eng. 17, 325 (2000)

34. K. M. Lee, Y. M. Jo, J. Mater. Cycle Waste Manag. 12, 212-219 (2010)

35. H. Minato, Standarizaton of Methods for Zeolite Speciality Determination and techniques for Zeolite resources utilization, Natural Zeolites - SOFIA'95 282-292 (1995)

36. J. Latosińska, E3S Web of Conferences 14, Energy and Fuels 2016, 14 (2017)

37. F. Espejel-Ayala, R. Schouwenaars, A. Durán-Moreno, R.M. Ramîrez-Zamora, Res Chem Intermediat 40, 2919-2928 (2014)

38. G. Yang, T. Yang, J Hazard Mater 62, 75 (1998) 